\title{
Cobertura política da imprensa, efeitos da mídia e adesão à democracia no Brasil após os protestos de 2013
}

\section{Political press coverage, media effects and adherence to democracy in Brazil after the protests of $\mathbf{2 0 1 3}$}

\author{
Uirá de Melo*, Pedro Santos Mundim**
}

*Mestre em Ciência Política pela Universidade Federal de Goiás, Brasil

**Professor Adjunto de Ciência Política da Universidade Federal de Goiás, Brasil

Resumo

\begin{abstract}
No Brasil, até 2013 os efeitos negativos dos casos de corrupção recaiam mais sobre a classe política do que à democracia. Mas frente à cobertura política da imprensa, que passou a tratar da falência da representação e das falhas do regime, esse artigo investiga os efeitos da mídia sobre o posicionamento dos cidadãos em relação ao sistema democrático. Com base em duas pesquisas de opinião pública nacionais realizadas em 2012 e 2014, estimamos os efeitos da exposição às notícias, uso da internet e atenção política sobre a adesão à comunidade política, o apoio à democracia e a performance do regime. Os resultados mostraram que a exposição às notícias passou a afetar, negativamente, as posições sobre o regime democrático. Isso não seria apenas mero reflexo da manipulação de corações e mentes de uma cobertura política mais negativa, segundo os adeptos da media malaise, mas uma evidência da capacidade dos cidadãos a serem mais críticos.
\end{abstract}

Palavras-chave: adesão à democracia; efeitos da mídia; media malaise; cidadãos críticos; Lapop

Abstract

Until 2013, the negative effects of corruption cases in Brazil used to fall more on the political class than on democracy. However, in the face of the political press coverage, which deals with the bankruptcy of representation and the regime's failures, this article investigates the media effects on the position of citizens in relation to the democratic system. Based on two a national public opinion polls conducted in 2012 and 2014, we estimate the effects of news exposure, internet use and political awareness on adherence to the political community, support for democracy and the regime performance. The results showed that the news exposure variable affected, negatively, the positions on the democratic regime. This would not be merely a reflection of the manipulation of hearts and minds of a more negative political coverage, according to media malaise supporters, but evidence of citizens' ability to be more critical.

Key words: adherence to democracy; media effects; media malaise; critical citizens; Lapop

No Brasil, o ano de 2013 ficou marcado pela proliferação de protestos nas grandes e médias cidades do país. Em abril surgiram os focos das primeiras manifestações motivadas, sobretudo, pelo discurso contra a tarifa de ônibus em cidades como São Paulo, Goiânia, Porto Alegre e Belo Horizonte. A violência policial contra manifestantes motivou novos eventos (Tavares, Roriz, \& Oliveira, 2016). Outras bandeiras surgiram, como a luta contra a corrupção e contra a aprovação da Proposta de Emenda Constitucional (PEC) no 37, que retirava autonomia e competência investigatória do Ministério Público Federal (Scherer-Warren, 2014). As manifestações ganharam ainda mais fôlego e chegaram ao seu ápice a partir da abertura da Copa das Confederações, em 15 de junho, sendo destaque nos maiores veículos da imprensa mundial.

Até hoje, diversas narrativas disputam espaço pela melhor interpretação desses eventos. Um veio recorrente é o da incapacidade das instituições representativas, especialmente o Congresso e o poder executivo, em 
dar vazão às demandas sociais, levando a críticas contundentes sobre o funcionamento da democracia do Brasil (Bringel, 2013; Bringel \& Geoffrey, 2015a, 2015b; Cohen \& Santana, 2015; Presusso \& Narvaes, 2015; Santos, 2013; Singer, 2013). Mas em um país redemocratizado há pouco mais de 30 anos, o que se impôs ao ponto de se cogitar a falência do regime político? E, de modo mais específico, a cobertura política da imprensa tive algum papel na conformação desse estado de opiniões sobre as instituições, o regime democrático e seu funcionamento?

A influência política dos meios de comunicação, em especial a sua vertente informativa, foi uma das principais fontes de preocupação dos estudos seminais do campo da comunicação política (CZitrom, 1982; Neuman \& Guggenheim, 2011). No Brasil, de acordo com Miguel (2002), são abundantes os estudos que abordam o impacto dos jornais impressos, dos telejornais e das propagandas eleitorais no comportamento político dos cidadãos, com escopo voltado, principalmente, para estudos de caso e de denúncias de interferência ilegítima, principalmente nas eleições presidenciais.

Para Miguel (2002), o entendimento da centralidade da mídia na teoria democrática passa pela compreensão desta instituição como meio em que os diversos discursos políticos são veiculados - onde se dá, por vezes, o debate entre correntes adversárias - e pelo entendimento de que os veículos de comunicação estão inseridos em uma realidade social que contribuem para construir e modificar. Por conta disso, é importante que os estudos sobre o seu poder de influência não se limitem ao papel desempenhado aos períodos eleitorais (Gomes, 2004), ou à cobertura de momentos críticos ligados a casos de corrupção (Aldé \& Vasconcellos, 2008; Miguel \& Coutinho, 2007), sem indicar problemas inerentes ao sistema político.

Até 2013, o regime democrático brasileiro não teria sido alvo da mídia em geral, e da imprensa em particular. Os efeitos negativos das narrativas sobre casos de corrupção frequentemente encontrados nos meios noticiosos, por exemplo, recaiam mais sobre a classe política per se, e as instituições ligadas a esses atores como os partidos e as casas legislativas, do que à democracia propriamente dita. Frente à cobertura política que, durante e após os protestos de 2013, passou a tratar tanto a falência da representação, quanto as falhas do regime (Souza \& Lima, 2014), esse artigo busca investigar os efeitos da cobertura política da imprensa para além da formação do comportamento eleitoral, especificamente, a influência sobre o posicionamento dos indivíduos em relação ao sistema democrático.

Na primeira parte do artigo discutimos questões ligadas à democracia e efeitos da mídia, em especial o debate sobre a capacidade de os meios de comunicação em mobilizarem, ou desmobilizarem, a adesão dos cidadãos ao regime democrático. Em seguida, apresentamos um método capaz de medir os efeitos da mídia em indicadores de adesão à comunidade política, apoio à democracia e performance do regime, inspirados nos estudos de Norris $(1999,2000)$ e Klingemann (1999) e com base nos dados do Barômetro das Américas (Lapop) de 2012 e 2014. ${ }^{1}$ Os resultados mostraram que a exposição às notícias afetou, negativamente, as opiniões sobre o regime democrático no Brasil entre esses dois pontos no tempo. Isso não seria apenas mero reflexo da manipulação de corações de mentes de uma cobertura política mais negativa, mas uma

\footnotetext{
1 O Lapop é uma pesquisa de opinião pública realizada em 34 países do hemisfério ocidental, com amostras nacionalmente representativas estratificadas em cada país. Informações detalhadas sobre as pesquisas são encontradas na página do Latin America Public Opinion Project, da Universidade de Vanderbilt. Barómetro das Américas - Projeto Latinoamericano de Opinião Pública (LAPOP), www.LapopSurveys.org. Agradecemos o Projeto de Opinião Pública Latino-Americana (LAPOP) e seus principais apoiantes (Agência dos Estados Unidos para o Desenvolvimento Internacional, Banco Interamericano de Desenvolvimento e Universidade de Vanderbilt) a disponibilização dos dados.
} 
evidência da sua capacidade de incentivar os cidadãos a serem mais críticos em relação às instituições, atores e regimes políticos.

\section{Democracia e efeitos da mídia: mobilização versus media-malaise}

Duas vertentes importantes analisam a existência de efeitos da mídia per si e os resultados dessa influência no posicionamento dos indivíduos em relação à democracia. De um lado encontra-se a linha de pensamento que sugere a capacidade de mobilização dos meios de comunicação; de outro, a que ficou conhecida na literatura como media-malaise, cuja ênfase recai na capacidade da mídia de desmobilizar, gerar apatia ou mesmo levar à expressão de valores negativos com respeito ao regime, seus princípios fundamentais, atores e instituições.

De acordo com Norris (2000), nos anos 1990 era majoritária a visão de que as mídias de massa, em especial a TV, influenciavam negativamente a participação cívica dos cidadãos. A teoria da espiral do cinismo é o melhor exemplo dessa linha de pensamento. Capella e Jamieson (1997) desenvolveram a ideia de que a maior presença de cobertura política estratégica - com foco nos indivíduos em detrimento dos temas e assuntos em debate -, com ênfase em termos que remetem à competição, guerra ou luta entre os atores, construía enquadramentos que direcionavam a audiência para reproduzir um comportamento cínico em relação aos políticos e instituições.

Miguel (2008) identifica outras duas hipóteses recorrentes na literatura que vinculam o declínio da confiança da opinião pública na política aos meios de comunicação. Uma centrada no fim das ilusões do público em relação aos políticos, resultado da tomada de consciência a partir das informações divulgadas na mídia; e outra fundamentada em uma melhora da percepção popular de que a qualidade da elite política decaiu em razão da adaptação dos atores políticos às atitudes e comportamentos impostos pela relação com jornalistas e resultantes da prática de produção de notícias.

Há outra linha de caráter estrutural e mais recente, com foco de análise voltado para a expansão, penetração e fragmentação da audiência, em especial da televisão, que considera também as preferências de consumo do público de cada meio de comunicação. Exemplo deste ramo de pesquisa foi elaborado por Prior (2007), que avaliou os resultados do aumento das opções de canais com o advento das TVs a cabo ou de meios como a internet, em contraponto com o período no qual as alternativas para os telespectadores estavam restritas às grandes redes nacionais de televisão. Ele concluiu que há sinais favoráveis tanto em direção à mobilização quanto à desmobilização.

Segundo Prior (2007), nos EUA, as grades de programação fixas das grandes redes de TV aberta faziam com que muitos indivíduos dedicassem involuntariamente atenção à cobertura política, aumentando seus conhecimentos sobre o assunto, com efeitos positivos nos índices de participação e identificação partidária. Mas o advento e crescimento das TVs a cabo fragmentou o público, propiciando especialização da audiência conforme as preferências de cada nicho - entretenimento e cobertura política (Baum \& Kernell, 1999). Nos anos 1970 e 1980, quando não existiam ainda os canais exclusivos de notícias, as TVs a cabo teriam diminuído, inclusive, o comparecimento eleitoral. Ademais, as opções de canais especializados em notícias ou entretenimento favorecem a polarização da audiência entre as facções políticas. Nos EUA, diversos autores constataram a crescente polarização política entre os eleitores e canais de notícias, jornais e 
programas de rádio, com efeitos substantivos (DellaVigna \& Kaplan, 2007; Iyengar \& Hahn, 2009; Iyengar \& Westwood, 2015; Prior, 2005, 2013; Stroud, 2011). Conforme sugerem Druckman, Peterson e Slothuss (2013), essa especialização do conteúdo em favor de um ou outro partido poderia levar a consequências negativas, como por exemplo: a inviabilização de consensos acerca de questões importantes; a geração de questionamentos constantes sobre a legitimidade dos processos eleitorais e decisões majoritárias; e maior afastamento da política de neófitos, moderados e independentes.

Essas influências negativas foram resumidas na expressão francesa malaise, que indica mal-estar ou doença, e atrelada à palavra video-malaise cunhada por Michael Robinson (Bennett, Rhine, Flikinger, \& Bennett, 1999), para depois ser expandida para media-malaise. No campo da comunicação política, essa expressão apontava para uma patologia social capaz de prejudicar o engajamento político e coletivo dos indivíduos, esgarçando o tecido social, de acordo com os paradigmas de Putnam (Gomes, 2008; Putnam, 1995a, 1995b), reduzindo o capital social positivo que torna as sociedades funcionais.

Essas conclusões pessimistas concorrem com as abordagens que veem de forma positiva os efeitos da mídia em relação à democracia. A principal expoente dessa visão é Norris $(1996,1999,2000)$, que em diversos estudos mostrou que a capacidade de mobilização dos meios de comunicação é parte do processo de modernização da sociedade. Ainda que negativos, os conteúdos da mídia contribuem para formar cidadãos críticos em relação à democracia, mas fortemente vinculados aos valores democráticos.

No Brasil, Mesquita (2008) e Schlegel (2005) investigaram como a cobertura política da imprensa afetaria a confiança nas instituições. O primeiro com foco na audiência do Jornal Nacional e o segundo nos dados sobre audiência de televisão, rádio, leitura de jornais e o horário eleitoral presentes no Estudo Eleitoral Brasileiro (ESEB) de 2002. ${ }^{2}$ Nenhum deles encontrou resultados que permitissem inferir efeitos significativos das variáveis midiáticas com respeito à confiança nas instituições e atores políticos.

Contudo, as análises implementadas neste artigo trazem duas diferenças. Mesquita e Schlegel utilizaram como variável dependente a confiança nas instituições, enquanto Norris e seus colaborados (1999), que tinham por objetivo analisar a baixa adesão ao sistema democrático, utilizaram uma elaboração mais extensa do conceito de democracia, que engloba outros aspectos do regime para além da confiança nas instituições. Este também será o nosso caso. Além disso, os dados das duas rodadas do Lapop permitem uma avaliação longitudinal dos efeitos, mais próxima da dinâmica dos efeitos da mídia encontrada em importantes estudos sobre o tema (Lazarsfeld, Berelson, \& Gaudet, 1948; Prior, 2007; Zaller, 1992a).

\section{Um modelo como inspiração}

Em Critical Citizens (Norris, 1999), a suposição de que a baixa participação em eleições e a baixa confiança nas instituições resulta em menor adesão ao regime democrático não se confirmou. Mas restou sem esclarecimento o fator que estimularia os altos níveis de insatisfação com o sistema democrático. Para solucionar esse problema, em Virtuous Circle Norris (2000) utilizou um desenho de pesquisa que lhe permitiu

\footnotetext{
${ }^{2}$ Assim como o Lapop, o ESEB é uma pesquisa de opinião pública nacional, com a diferença de ser realizada, desde o pleito de 2002, logo após o termino das eleições presidenciais brasileiras. Outras informações sobre o survey encontram-se na página do Centro de Estudos de Opinião Pública (CESOP), da Unicamp. Disponível em: <https://www.cesop.unicamp.br/por/eseb $>$.
} 
analisar como índices de atenção política e exposição à mídia influenciavam a adesão à democracia e aos valores desse regime.

Norris (2000) identificou correlações positivas entre o tempo dedicado à cobertura política e o aprendizado político; relações positivas ou neutras com respeito à confiança nas lideranças políticas e instituições governamentais; e, por fim, concluiu que a cobertura política contribuía para "ativar o ativismo" dos grupos já interessados em temas políticos, independente do meio de comunicação (internet, impresso ou televisivo). A correlação positiva se estendia também para questões mais abstratas: apoio a ideais democráticos, avaliação da performance do regime político e confiança nas instituições. No entanto, a autora fez a ressalva de que a simples correlação positiva entre atenção à cobertura política e estas últimas variáveis não indicaria uma relação de causalidade. Tal relacionamento poderia ser efeito de predisposições entre os pesquisados, pois aqueles que dedicavam tempo ao noticiário político já detinham inclinações favoráveis ao regime e suas instituições.

Norris (2000) também mostrou que o apoio à democracia se manteve alto nos países que pesquisou, mas que a insatisfação em relação à performance do regime aumentou. Este resultado está em consonância com o que foi encontrado em Critical Citizens. Para mensurar o desempenho da democracia em ambas as obras foi necessário traçar critérios para os quais havia dados disponíveis e que abarcassem um rol de variáveis dependentes mais importantes ligadas a esse regime político. Expandiram-se, assim, os parâmetros do estudo seminal de Easton (1975): o apoio à comunidade política; suporte ao regime, incluindo princípios, performance e instituições; e apoio aos atores políticos (Norris, 2000). Os dados também deveriam permitir análise estatísticas capazes de clarificar o efeito da cobertura política da TV, do rádio, dos jornais impressos e da comunicação dos partidos políticos na adesão à democracia.

Em Critical Citizens e Virtuous Circle foram feitas análises de conteúdo da cobertura política da imprensa. Para deixar clara a influência das variáveis midiáticas, Norris incluiu como variáveis de controle em seus modelos indicadores estruturais (educação, gênero, idade e renda) e atitudinais (interesse político e posicionamento ideológico). Os dados utilizados foram do World Values Survey (WVS), o que possibilita estudos comparativos entre diversos países ou de corte transversal para um único país. Contudo, ao longo dos anos, os questionários do WVS sofreram alterações e as perguntas que contribuíram para geração de dados que possibilitaram a construção dos índices utilizados em Critical Citizens foram modificadas.

Diante desse problema, e das restrições de disponibilidade e reprodutibilidade da pesquisa de Norris com dados mais recentes, optou-se por seguir os passos do capítulo elaborado por Klingemann (1999) em Critical Citizens. $\mathrm{O}$ autor se atém às categorias de Easton para quantificar a adesão à democracia. Para além do desempenho de mandatários, o estudo da adesão ao regime deve captar a percepção dos indivíduos relativamente aos seus objetos mais essenciais: o senso de comunidade política; a performance do regime e suas instituições mais basilares (partidos, parlamento e governo); e os ideais que este tipo de organização da vida política enseja. ${ }^{3}$

Assim como Norris, Klingemann trabalhou com os dados de rodadas do WVS realizadas nos anos 1990. Isso trouxe problemas para os objetivos deste artigo. As perguntas utilizadas para construir os indicadores que

\footnotetext{
${ }^{3}$ Klingemann (1999) distingue estes três objetos da seguinte maneira: "A comunidade política é a identidade cultural que transcende particularidades das estruturas formais de governo e engloba a identidade elementar da coletividade constituinte do regime. O regime é constituído pelos princípios, processos e instituições formais que persistem e transcendem mandatários particulares".
} 
medem as três dimensões de adesão à democracia foram modificadas, ou substituídas, nos questionários mais recentes da WVS aplicados no Brasil, em 2006 e 2014, o que impede a reprodutibilidade das análises do autor. A lacuna temporal de quase 10 anos entre as duas pesquisas também deixaria a comparação instável. Optou-se, assim, pela utilização de banco de dados do Lapop.

\section{Mudanças de conteúdo e enquadramento da cobertura política da imprensa}

Segundo Almond e Verba (1989), a cobertura política da imprensa contribui para a orientação cognitiva e afetiva e para a avaliação dos indivíduos sobre o sistema democrático. Além disso, no caso brasileiro, ela é considerada um ator político decisivo em diversos momentos históricos, seja da transição no período entre 1954-64 (Sodré, 2004), seja nas eleições após a redemocratização (Biroli \& Miguel, 2013; Mundim, 2014; Rubim \& Azevedo, 1998).

Nos testes realizados por McAllister (1999), o acesso à mídia demonstrou ter papel relevante para a desconfiança em relação às instituições democráticas e aos atores políticos. Cappella e Jamieson (1997) encontraram resultados semelhantes. Mas, conforme a crítica de Norris (2000), descartaram o fato de que o cinismo com que os eleitores interpretavam os políticos e as instituições poderia advir de promessas não cumpridas, políticas públicas fracassadas, performances políticas fracas ou mesmo da manipulação eleitoral de slogans, negativismo ou ataques às instituições vigentes.

Esses critérios estão relacionados com a noção de responsividade da representação vinculada à ideia de democracia (Rennó, 2013). Mas existem entraves para a boa responsividade, resultantes do lobby de atores com mais recursos financeiros e de grandes esquemas de corrupção, que têm a capacidade de subverter preferências dos parlamentares e as políticas do executivo. São justamente essas questões que estão relacionadas ao exercício de fiscalização das autoridades e das instituições pela imprensa, no seu papel de cão de guarda.

Portanto, os resultados das análises multivariadas devem ser interpretados, principalmente, à luz da dinâmica da cobertura política da imprensa no Brasil entre 2012 a 2014. Estamos cientes de que, nos dias de hoje, é impossível que os meios de informação tradicionais monopolizem o fluxo informacional sobre protestos e manifestações. Como mostram diversos estudos sobre junho de 2013, grupos de midiativismo apresentaram enquadramentos mais positivo dos manifestantes, contestaram as narrativas apresentadas $\mathrm{e}$ trouxeram informações adicionais sobre os acontecimentos que não ganhavam espaço em telejornais e veículos de imprensa (Bentes, 2014; Fontanetto \& Bezerra, 2016; Moretzsohn, 2014; Schneider, Perissé, \& Kleinsorgen, 2014; Ziller, 2014). Mas entendemos que as produções desses mesmos grupos reforçaram, e não relativizaram, as críticas que foram apresentadas em relação ao funcionamento da democracia no Brasil. Não se pode dizer, também, que eles tenham conseguido substituir, em extensão, o alcance e penetração da televisão e das notícias televisivas, por exemplo.

Dito isso, pode-se pergunta: como a imprensa brasileira se posicionou em relação às instituições e ao regime entre 2012 e 2014? Miguel e Coutinho (2007) constataram que os jornais de maior circulação e alcance nacional priorizaram, desde a descoberta do escândalo do Mensalão, a participação individual de parlamentares e membros do governo nas tramoias relativas ao desvio de recursos para a compra de votos de políticos e formação de "caixa 2". Aldé e Vasconcellos (2008) encontraram resultado semelhante e 
concluíram que os veículos de informação deram ênfase ao viés dramático do escândalo em detrimento de uma cobertura voltada para apontar questões estruturais da democracia, tais como a relação executivolegislativo e o financiamento de campanhas eleitorais. Os autores identificaram, ainda, a participação mais efetiva das chamadas mídias digitais (blogs, vlogs, sites de notícias independentes) ${ }^{4}$ vinculadas a coberturas independentes por jornalistas ou outros profissionais cujas revelações tinham repercussão entre a classe política e a sociedade.

Outro ponto de relevância teórica e factual é a constatação de Althaus (2006) sobre o consumo de notícias durante momentos de crise nos EUA. Em pesquisa efetuada a respeito do tema no período de 13 meses, sendo o mês de setembro de 2001 o ponto mediano, constatou-se elevação no consumo de notícias em decorrência do ataque às torres gêmeas em 11 de setembro. Infelizmente, no Brasil, não há dados disponíveis de análises de conteúdo ou de pesquisas semelhantes à de Althaus. Mas as manifestações de junho de 2013 representam um momento crítico na política nacional. Elas ganharam ampla repercussão e visibilidade na imprensa e tornaram-se o principal tema do noticiário. Em um período de poucos dias, a desqualificação generalizada que marcou o início da cobertura sobre as manifestações deu lugar ao apoio aos protestos considerados "pacíficos" e suas reivindicações, ainda que com críticas ao vandalismo (Borges, 2015; Carlos, 2015; Lima \& Loose, 2014; Souza \& Morales, 2016; Zanotti, 2014).

Em uma análise interessante, Pinto (2017) sustenta que os efeitos da trajetória discursiva das manifestações de 2013 tiveram efeitos de longo prazo. A partir desses eventos, sedimentou-se um cenário de críticas ao PT e à ex-presidente Dilma Rousseff, cuja repercussão influenciou a política nacional nos anos posteriores. Mas é possível dizer mais. A cobertura sobre as manifestações iniciou o processo que também levou à esfera pública temas adjacentes, como a desaprovação ao funcionamento das instituições, a crítica aos políticos, a insatisfação com as políticas públicas e com a democracia.

Análises de conteúdo feitas pelo Manchetômetro mostram, por exemplo, como as notícias sobre a política e o governo federal eram enquadrados, principalmente, de maneira negativa a partir de $2014 .{ }^{5}$ Outra forma de avaliar esse movimento é com base na percepção do público sobre o noticiário. Desde 2004 a pesquisa CNI-Ibope pergunta trimestralmente aos brasileiros como eles avaliam a cobertura da imprensa sobre o governo. O gráfico da figura 1 mostra a evolução dessa série entre 2007 e 2015. A linha pontilhada representa o valor médio. Após um longo período de saldo positivo, junho de 2013 representa um ponto de virada na percepção do público.

\footnotetext{
${ }^{4}$ São classificadas como mídias digitais os veículos de comunicação surgidos após a internet e com base exclusiva nesta plataforma, por conseguinte, incluem-se entre os não digitais jornais impressos, revistas e TV a despeito de a maioria destes meios terem plataformas espelhadas na internet.

${ }^{5}$ Conforme é informado na página do Manchetômetro, este "é um website de acompanhamento da cobertura da grande mídia sobre temas de economia e política e não tem qualquer filiação com partido político ou grupo econômico". Disponível em: <http://www.manchetometro.com.br/>. Acesso em: 06 de jun. 2018.
} 
Figura 1: Evolução da percepção do público sobre a cobertura da imprensa sobre o governo

Saldo da percepção da cobertura (favorável - desfavorável)

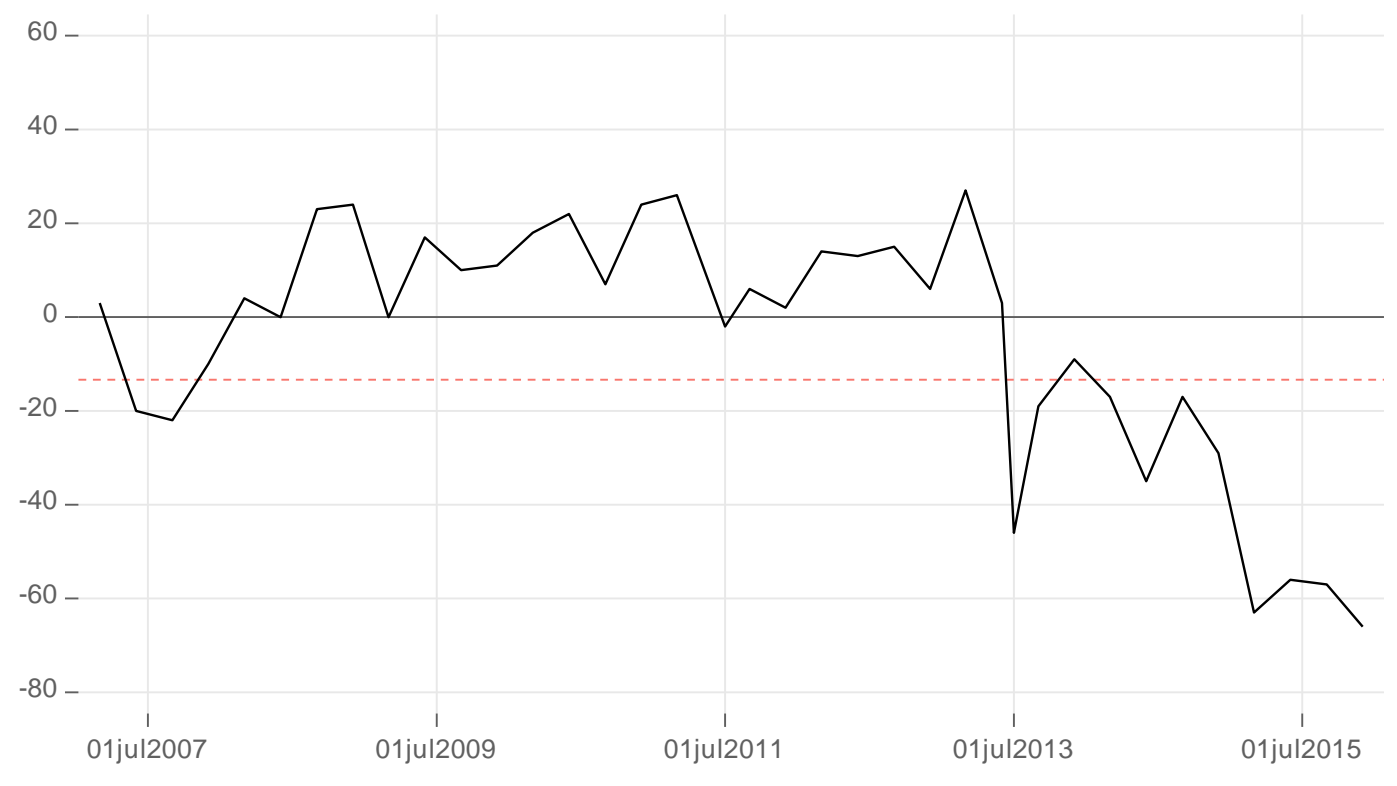

Fonte: CNI-Ibope

Essa é uma evidência da mudança qualitativa do conteúdo da cobertura política da imprensa, para um viés mais negativo, e do nível de atenção e percepção dos brasileiros em relação aos temas políticos. Após as manifestações de 2013, a imprensa política entrou em um permanente estado de alerta. Afinal, protestos continuaram a acontecer no país. Casos e escândalos de corrupção envolvendo figuras e partidos importantes, além das críticas ao funcionamento dos serviços públicos, não desapareceram. Na verdade, tornaram-se mais frequentes. A realização da Copa do Mundo de 2014 e as eleições presidenciais também contribuíram para que essas questões permanecessem salientes na cabeça dos jornalistas e cidadãos.

Embora não tenha sido efetuada uma análise de conteúdo das matérias publicadas, pode-se levantar a hipótese de que os efeitos da cobertura política da imprensa sobre a opinião dos brasileiros em relação à democracia mudaram entre 2012 e 2014. Se, antes de 2013, a correlação entre exposição às variáveis midiáticas tenderia, de uma maneira geral, a ser positiva, a partir de junho de 2013 essa associação passou a ser negativa. A única explicação plausível para isso é uma mudança na forma de apresentação do conteúdo. 


\section{Descrição dos dados: Lapop 2012 e Lapop $2014^{6}$}

As perguntas selecionadas dos questionários do Lapop em 2012 e 2014 buscaram reproduzir o exercício efetuado por Klingemann (1999) e identificar as dimensões elaboradas a partir dos conceitos de Easton (1975). Mas há mudanças relevantes entre as duas pesquisas. A principal é a diferenciação entre as perguntas aplicadas em 2012 para questionários de números ímpares e pares. Levando-se em conta estas modificações e em concordância com a construção e conteúdo das perguntas, optou-se por se estabelecer a organização das dimensões da democracia a partir das questões abaixo. Deu-se prioridade às perguntas aplicadas à toda amostra nos dois anos.

\section{Variáveis dependentes: as dimensões de adesão à democracia}

As variáveis dependentes buscaram medir o grau de adesão à comunidade política, o seu apoio à democracia como uma forma ideal de governo e a avaliação que se faz a performance do regime democrático. ${ }^{7}$

A adesão à comunidade política foi composta por uma bateria de quatro perguntas. Todas tinham como opção de resposta uma escala de 1 a 7, em que 1 significava "nada' e 7 "muito".

Até que ponto o(a) sr./sra. tem respeito pelas instituições políticas do Brasil?

Até que ponto o(a) sr./sra. acredita que os direitos básicos do cidadão estão bem protegidos pelo sistema político brasileiro?

Até que ponto o(a) sr./sra. se sente orgulhoso de viver no sistema político do Brasil?

Até que ponto o(a) Sr.(a) acha que se deve apoiar o sistema político brasileiro?

O apoio à democracia como uma forma ideal de governo foi medido por uma única pergunta, que deveria ser respondida numa escala de 1 a 7, em que 1 representava "discorda muito" e 7 "concorda muito":

Mudando de assunto de novo, a democracia tem alguns problemas, mas é melhor do que qualquer outra forma de governo. Até que ponto concorda ou discorda desta frase?

Por fim, mediu-se a performance do regime com uma bateria de três perguntas. Em duas delas as opções estavam na escala de 1 a 7, em que 1 significava "nada" e 7 "muito". Na terceira, as opções de resposta estavam distribuídas numa escala ordinal de satisfação com quatro opções de resposta.

Até que ponto o(a) sr./sra. tem confiança nos partidos políticos?

Até que ponto o(a) sr./sra. tem confiança na Presidenta da República?

\footnotetext{
${ }^{6}$ Lapop 2012: amostra nacional e 1500 entrevistas, realizadas entre $1^{\circ}$ de março e 18 de abril, com margem de erro de $\pm 2.5 \%$. Lapop 2014: amostra nacional e 1500 entrevistas, realizadas entre 21 de março e 27 de abril, com margem de erro de $\pm 2.5 \%$. Outras informações técnicas das pesquisas encontram-se disponíveis na página do Lapop.

${ }^{7}$ A construção de cada um desses índices foi precedida de análises fatoriais confirmatórias (Figueiredo Filho \& Silva Júnior, 2010; Mingoti, 2005).
} 
De uma maneira geral, o(a) sr./sra. está muito satisfeito(a), satisfeito(a), insatisfeito(a) ou muito insatisfeito(a) com o funcionamento da democracia no Brasil?

As estatísticas descritivas de cada uma das variáveis dependentes encontram-se na tabela 1. Vale dizer que algumas perguntas do questionário do Lapop 2012 separaram os respondentes em dois grupos. Por isso, apenas metade da amostra respondeu à pergunta usada para medir o apoio à democracia como uma forma ideal de governo. Daí o menor número de respostas em relação a 2014.

Tabela 1: Estatísticas descritivas das variáveis de adesão à democracia.

\begin{tabular}{lllllll}
\hline & Obs. & Média & Desv. Pad. & Min. & Max. & Alpha \\
\hline Lapop 2012 & & & & & & \\
$\quad$ Adesão à comunidade política & 1448 & 14.61 & 5.84 & 4 & 28 & 0.8141 \\
Performance do regime & 707 & 10.32 & 3.02 & 3 & 18 & 0.5870 \\
Apoio à democracia & 1432 & 5.23 & 1.77 & 1 & 7 & \\
Lapop 2014 & & & & & & \\
Adesão à comunidade política & 1470 & 12.81 & 5.89 & 4 & 3076 \\
Performance do regime & 1441 & 8.24 & 3.44 & 3 & 18 & 0.5870 \\
Apoio à democracia & 1459 & 4.97 & 1.82 & 1 & 7 &
\end{tabular}

Fonte: Lapop 2012 e 2014. Teste t rejeitaram a hipótese nula para igualdade de variâncias em todas as diferenças nas médias entre as duas pesquisas ao nível de 0.001 .

\section{As variáveis independentes}

As variáveis de independentes foram compostas por cinco grupos. Os três primeiros seguem a proposta de Norris (2000), com variáveis estruturais: sexo, idade, escolaridade e porte do município; ${ }^{8}$ atitudinais e comportamentais: interesse político, participação política e posicionamento ideológico; e de uso de mídia: atenção às notícias, uso da internet e atenção política. O quarto grupo é composto por variáveis políticas clássicas de avaliação do governo e da economia do país. O quinto grupo é inspirado no trabalho de Ceobanu, Wood e Ribeiro (2011), que relaciona o impacto do crime e da violência com a adesão a valores democráticos.

\section{Variáveis atitudinais e comportamentais}

Embora seja uma das variáveis mais utilizadas nos estudos sobre opinião pública, encontrar uma forma adequada de medir a ideologia ainda é um desafio. O formato mais usado é pedir ao do entrevistado que se posicione numa escala numérica que vai da esquerda para a direita. Contudo, o fato de as pessoas

\footnotetext{
${ }^{8}$ Essas variáveis foram codificadas da seguinte maneira: sexo: $1=$ homem e $0=$ mulher; idade: $1=16$ a 24 anos, $2=25$ a 34 anos, $3=35$ a 44 anos, $4=45$ a 59 anos e $5=60$ anos ou mais; escolaridade: $1=$ ensino fundamental, 2 = ensino médio e 3 = ensino superior; e porte do município: 1 = pequeno, 2 = médio e 3 = grande.
} 
confundirem o significado de esquerda e direita compromete a validade dos indicadores e aumenta as taxas de não-respostas (Turgeon \& Oliveira, 2015; Wood \& Oliver, 2012).

Wood e Oliver (2012) propuseram uma nova forma de medir a ideologia, capaz de diminuir tanto o problema da inconsistência do indicador, tornando-o mais confiável, quanto o das não-respostas. 0 auto posicionamento do entrevistado na escala numérica de esquerda e direita é recodificado em variáveis binárias de esquerda, direita e não-respostas, sendo o centro a categoria de referência. Como estudos de opinião pública mostraram que a escolaridade aumenta a consistência das respostas dos entrevistados em relação à ideologia (Converse, 1964; Turgeon \& Oliveira, 2015), os indicadores binários de ideologia são interagidos com a escolaridade.

No Lapop, pede-se aos entrevistados que se posicionem numa escala de vai de 1 a 10, sendo 1 "esquerda" e 10 "direita". Pessoas que se posicionaram entre 1 e 4 foram classificadas como de esquerda; entre 6 e 10, como de direita; e as não-respostas foram classificadas como não tendo ideologia. Nos modelos multivariados, os indicadores de esquerda e direita foram interagidos com as medidas de escolaridade média e superior.

O interesse por política e a participação política são outras duas variáveis deste grupo. No primeiro caso, utilizou-se a pergunta sobre o nível de interesse por política do entrevistado, numa escala ordinal de quatro pontos: nada, pouco, algo e muito. No segundo, mediu-se a participação política a partir de um índice, composto por vários tipos de pergunta. Incluiu-se tanto aquelas que buscam medir a participação política tradicional, como frequentar reuniões de partidos políticos, quanto não-tradicional, como ir a protestos e manifestações. Optou-se, também, por incluir a participação comunitária como ato político, uma vez que este tipo de associação demanda algum tipo de posicionamento em relação ao poder incumbente.

As variáveis cujas opções de resposta eram sim ou não foram transformadas em indicadores binários, sendo 1 para a respostas positivas e zero para as demais. Em seguida, elas foram somadas com as variáveis cujas respostas eram escalas ordinais de intensidade temporal, que iam de nunca até uma vez por semana. A descrição dos índices constituídos encontra-se na tabela 2.

Tabela 2: Estatísticas descritivas dos índices de atenção política

\begin{tabular}{lllllll}
\hline & Obs. & Média & Desv. Pad. & Min. & Max. & Alpha \\
\hline Lapop 2012 & 1488 & 2 & 0,872244 & 2 & 8 & 0.3929 \\
Lapop 2014 & 1491 & 2 & 0,874498 & 2 & 8 & 0.4198 \\
\hline
\end{tabular}

Fonte: Lapop 2012 e 2014

\section{Variáveis midiáticas}

Embora o foco principal deste artigo seja nos efeitos da cobertura política da imprensa nas medidas de adesão à democracia, foram utilizados os três tipos de variáveis midiáticas disponíveis nas pesquisas do Lapop. Em ambas se perguntou com que frequência se prestava atenção às notícias, independente do meio de comunicação utilizado, e com que frequência se usava a internet. A distribuição das respostas encontrase na tabela 3. Os dados parecem corroborar a constatação de Althaus (2006) sobre o aumento do nível de consumo de notícias após momentos de crise, especialmente porque a atenção às notícias apresentou uma 
taxa de crescimento de $43 \%$ entre 2012 e 2014, um valor expressivo para ser condicionado apenas à chance ou algum tipo de modificação no fluxo do questionário.

Tabela 3: Distribuição da frequência de exposição às noticias e do uso da internet (\%)

\begin{tabular}{lllll}
\hline & \multicolumn{2}{l}{ Atenção às notícias } & \multicolumn{2}{l}{ Usa a internet } \\
\hline \multirow{2}{*}{ Lapop 2012 } & Lapop 2014 & Lapop 2012 & Lapop 2014 \\
\cline { 2 - 5 } Raramente & 5.7 & 1.0 & 37.6 & 39.9 \\
Algumas vezes por mês & 7.1 & 5.1 & 12.7 & 6.8 \\
Algumas vezes por semana & 7.4 & 1.5 & 5.3 & 3.7 \\
Diariamente & 30.0 & 21.1 & 15.9 & 12.6 \\
$\mathrm{~N}$ & 49.8 & 71.3 & 28.4 & 37.1 \\
& 1480 & 1500 & 1500 & 1500 \\
\hline
\end{tabular}

Fonte: Lapop 2012 e 2014

Preferiu-se manter a distinção entre os veículos ao invés de se construir um único índice. Essa diferença é importante, pois o uso da internet no Brasil tem um claro corte geracional, conforme aponta a Pesquisa Brasileira de Mídia 2015 (Brasil, 2014). Ao contrário, por exemplo, do que acontece com a televisão, há maior uso diário da internet entre os entrevistados jovens, de 16 a 35 anos, e de escolaridade mais alta. Esse fato torna-se ainda mais relevante frente à constatação de que os protestos de 2013 foram compostos majoritariamente por jovens de classe média (Scherer-Warren, 2014; Singer, 2013).

Esse dado talvez explique o percentual relativamente alto de entrevistados que disseram não usar a internet. Se considerássemos apenas uma exposição mais elevada ao meio (algumas vezes por semana e diariamente), algo próximo de $50 \%$ das pessoas não poderiam usar as novas mídias para se informar, já que elas simplesmente por não as utilizarem. Essa é uma outra evidência de que, até 2014, as informações veiculadas pelas novas mídias ainda não teriam conseguido substituir o alcance e penetração dos meios de informação tradicionais, especialmente a televisão e as notícias televisivas, junto à população brasileira.

A última variável midiática é derivada de um índice de atenção política (Mundim, 2010; Zaller, 1991, 1992b; Zaller \& Price, 1993). Em cada uma das pesquisas foram feitas perguntas de conteúdo factual, como por exemplo qual era o nome do presidente dos EUA. ${ }^{9}$ Cada uma delas foi recodificada em variáveis binárias. Para as respostas certas deu-se o valor de 1, para as demais o valor de 0 . Em seguida, os novos indicadores foram somados, constituindo-se os índices de atenção política, cuja descrição encontra-se na tabela 4.

\footnotetext{
${ }^{9}$ No Lapop 2012, as perguntas que compuseram o índice atenção política foram: "Qual é o nome do atual presidente dos Estados Unidos?", "De quanto tempo é o mandato do presidente no Brasil?" e "Quantos deputados tem o Congresso Federal?". No Lapop 2014, foram: "Qual é o nome do atual presidente dos Estados Unidos?", "Em qual continente fica a Nigéria?", "De quanto tempo é o mandato do presidente no Brasil?" e "Quantos deputados tem o Congresso Nacional?".
} 
Tabela 4: Estatísticas descritivas dos índices de atenção política

\begin{tabular}{lllllll}
\hline & Obs. & Média & Desv. Pad. & Min. & Max. & Alpha \\
\hline Lapop 2012 & 1497 & 1.78 & 0.80 & 0 & 3 & 0.4525 \\
Lapop 2014 & 1500 & 2.06 & 1.16 & 0 & 4 & 0.5906 \\
\hline
\end{tabular}

Fonte: Lapop 2012 e Lapop 2014

Variáveis sobre crime, vitimização e justiça

Os Lapop de 2012 e 2014 trazem perguntas sobre crime, vitimização e justiça. No primeiro caso, perguntouse ao entrevistado sobre a sua sensação de segurança no lugar onde vive, numa escala ordinal de quatro pontos: muito inseguro(a), pouco inseguro(a), pouco seguro(a) e muito seguro(a). No segundo, se foi vítima de algum tipo de crime nos últimos doze meses $(1=\operatorname{sim}$ e 0 = não). No terceiro, em caso de ser vítima de roubo ou assalto, o quanto confiaria na capacidade de o sistema judiciário punir o culpado, também numa escala ordinal de quatro pontos: nada, pouco, algo e muito. Elas foram incluídas na análise porque o trabalho de Ceobanu, Wood e Ribeiro (2011) mostrou, de maneira interessante e convincente, o impacto do crime e da violência na adesão a valores democráticos.

\section{Resultado dos modelos}

Foram estimados três modelos de regressão linear por mínimos quadrados para avaliar a relação entre as variáveis explicativas descritas anteriormente com os indicadores de adesão à democracia. ${ }^{10}$ Para essa análise, os bancos de dados das pesquisas do Lapop 2012 e 2014 foram agregados, transformando-se em apenas um. Para captar o efeito das variáveis midiáticas na mudança de opinião dos entrevistados sobre a democracia brasileira entre essas duas rodadas, interagimos os indicadores de exposição às notícias, uso de internet e atenção política com o indicador da base de dados de 2014. Os resultados encontram-se nos gráficos da figura $2 .^{11}$

\footnotetext{
${ }^{10}$ Foram realizados testes de pós-estimação para todos os modelos. Não foram encontrados problemas de multicolinearidade, normalidade dos resíduos e de especificação.

${ }^{11} \mathrm{~A}$ tabela completa com os modelos e os coeficientes estimados de todas as variáveis explicativas encontrase no apêndice do artigo.
} 
Figura 2: Coeficientes estimados do efeito das variáveis midiáticas sobre os indicadores de adesão à comunidade política, apoio à democracia e performance do regime.

Os três gráficos superiores mostram os efeitos das variáveis midiáticas em 2012, e os gráficos inferiores mostram os efeitos das variáveis midiáticas em 2014. As linhas indicam o intervalo de confiança de $95 \%$ dos coeficientes estimados.

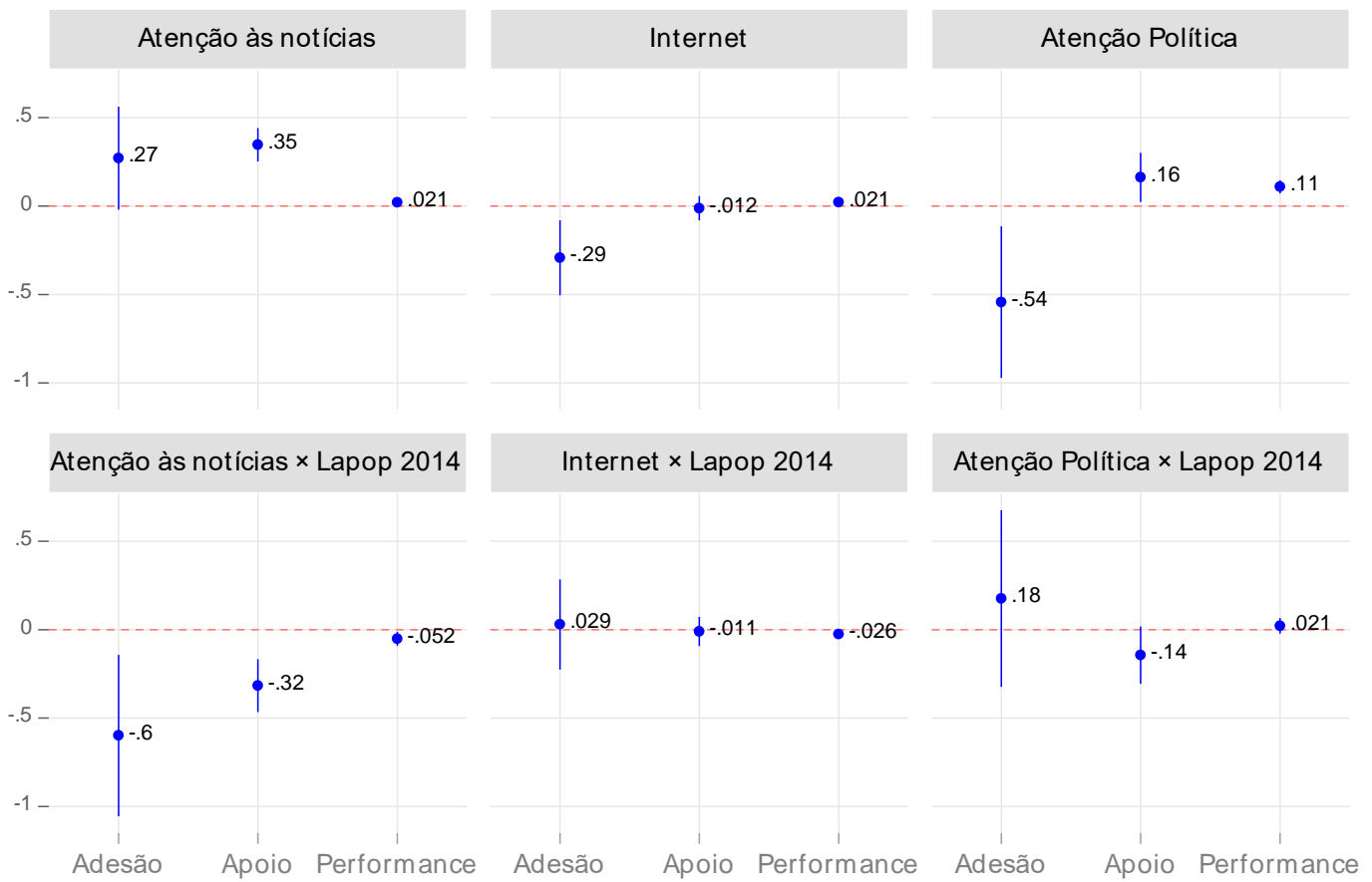

Conforme esperado, os dados sugerem uma mudança nos efeitos das variáveis midiáticas sobre os indicadores de adesão à democracia. Isso fica claro, de maneira mais contundente, na medida de atenção às notícias, cujo efeito passou de positivo em 2012 para negativo em 2014. Dito de outro modo, em 2012, exposição às notícias gerava um aumento dos valores de adesão à comunidade política e apoio à democracia. Justamente o contrário passou a ocorrer em 2014, como mostram os termos interativos e os sinais negativos dos coeficientes. Agora, quanto maior a exposição às notícias, menor a preferência dos entrevistados pela democracia, em detrimento de outros regimes.

A discussão sobre a atenção política é menos direta. Quando desenvolvido por Zaller (1992b), esse indicador buscava captar justamente o grupo de indivíduos mais expostos às informações políticas e, por isso mesmo, mais capazes de interagir e processar, de maneira complexa e especializada, as questões que envolvem o mundo da política e das políticas públicas. Por essa razão, é natural que os indivíduos com maior atenção política já tivessem, em 2012, visões críticas sobre a comunidade política brasileira, mas, ao mesmo tempo, demonstrassem um apoio à democracia como forma de governo em comparação com outras. $\mathrm{O}$ assustador é observar que, em 2014, os efeitos negativos tenham permanecido, no primeiro caso, e os efeitos positivos desaparecido, no segundo.

Por fim, a variável que mede o uso da internet. Pesquisa de opinião feita pelo Ibope Inteligência, a pedido da Rede Globo, mostrou que a maior parte dos manifestantes de julho de 2013 tinha escolaridade e renda 
familiar mensal acima da média brasileira, e eram mais jovens. ${ }^{12}$ De acordo com os dados da PBM 2015 (Brasil, 2014), é junto a esse público que as novas mídias são mais utilizadas.

Os dados mostram, portanto, que tais grupos já apresentavam, em 2012, insatisfação com os rumos de duas dimensões da democracia brasileira: a adesão à comunidade política e a performance do regime. Mostram, também, e talvez na direção contrária do que se esperava, que o efeito do uso da internet para uma visão mais negativa ao regime se diluiu a partir dos protestos de 2013 . Tudo sugere que ele deixou de ser algo de um grupo específico para tornar-se mais generalizado, ampliando-se para grupo de pessoas menos envolvidas com política. Assim, o fato de as redes sociais terem sido a principal fonte de mobilização dos manifestantes não deve ser confundida com o seu efeito sobre a opinião pública em relação ao regime. Neste ponto, pode-se perguntar: a cobertura política da imprensa, no Brasil, teria incentivado à mobilização ou à desmobilização? O que se viu foi um claro efeito de media-malaise? Ou teríamos observado a emergência de cidadãos críticos? As análises implementadas não nos permitem responder com exatidão à primeira pergunta. Mas a nossa histórica política recente sugere que o Brasil passou por um intenso período de mobilização, independente das nossas opiniões a respeito da legitimidade desses movimentos.

Em relação às outras duas perguntas, a resposta seria sim, para ambas. Os dados sugerem, de maneira razoável, não apenas uma piora dos indicadores de avaliação das instituições e atores político e, consequentemente, do regime democrático no Brasil, mas uma correlação negativa entre tais indicadores e a cobertura política da imprensa: quanto maior a exposição às notícias, menor as notas ou valores obtidos na adesão à comunidade política e no apoio ao regime democrático. Isso não seria apenas mero reflexo da manipulação de corações de mentes de uma cobertura política mais negativa, mas uma evidência da sua capacidade de incentivar os cidadãos a serem mais críticos em relação às instituições, atores e regimes políticos. Ou seja, nossas interpretações dos resultados dos modelos dão respaldo à uma visão próxima à de Norris.

\section{Conclusão}

No Brasil, o período entre 2012 e 2014 ficou marcado por acontecimentos sociais e políticos de grande significância que envolveram manifestações populares, escândalos de corrupção, disputas eleitorais e torneios de futebol internacionais organizados pela FIFA. Como não poderia deixar de ser, todos ganharam ampla repercussão na imprensa tradicional e nas novas mídias. Esse cenário nos remete a algo semelhante ao descrito por Converse (1962), que destacou como a busca por informações políticas é influenciada pela intensidade da oferta desse produto na sociedade e pela motivação dos indivíduos em acessar os fluxos disponíveis de informação e opinião.

Conforme ressalta Miguel (2000), a mídia está inserida no âmbito social e contribui ao mesmo tempo para modificá-lo. Ela tem papel central para a política, pois é o meio em que os diversos discursos são veiculados.

\footnotetext{
${ }^{12}$ Por exemplo, 43\% dos manifestantes tinha escolaridade superior, 85\% renda acima de 2 salários mínimos e $43 \%$ entre 14 e 24 anos. Segundo dados do IBGE, as proporções dessas características na população brasileira são, respectivamente, $19 \%, 22 \%$ e $17 \%$. Pesquisa nas capitais de SP, RJ, MG, RS, PE, CE, BA e em Brasília na quinta-feira, dia 20/07/2013. Foram entrevistados 2002 manifestantes com 14 anos ou mais, com margem de erro de $\pm 2 \%$. Disponível em: <http://g1.globo.com/brasil/noticia/2013/06/veja-integrada-pesquisa-do-ibope-sobre-os-manifestantes.html>. Acesso em: 12 fev. 2018.
} 
Dentro desse contexto, este artigo deu seguimento a trabalhos como os de Mesquita (2008) e Schlegel (2005), que investigaram os efeitos da cobertura política da imprensa junto à confiança nas instituições. Mas apresentou ao menos duas novidades. A primeira foi a análise de outros aspectos da democracia para além da confiança institucional: o sentimento de pertencimento à comunidade política e sua expressão como ideal. A segunda são os resultados.

Ao contrário dos estudos de Mesquita e Schlegel, as análises implementadas aqui encontraram efeitos da mídia sobre a opinião política dos cidadãos e sugerem que a cobertura política da imprensa gerou indivíduos mais críticos em relação ao desempenho do regime. Ou seja, elas levaram a uma piora nos indicadores de avaliação do regime democrático no Brasil entre 2012 e 2014. Parte dessa insatisfação advém de vieses midiáticos que, ao criticarem personagens e partidos, o fazem sem distinguir entre vícios privados e problemas intrínsecos ao sistema, colocando em questão a própria democracia. Outra consequência prática desses efeitos parece ser a adesão de parte dos cidadãos, em pesquisas eleitorais recentes, a candidatos que representam tendência autoritária.

O aumento da crítica em relação a qualquer regime não é, por si, nocivo, especialmente porque elas são importantes para o seu aprimoramento. Contudo, se levarmos em conta a mudança dos efeitos das variáveis midiáticas entre 2012 e 2014, e o fato de termos uma cobertura política da imprensa mais negativa, abrese a possibilidade para que a insatisfação extrapole as questões hodiernas das manchetes da mídia não apenas sobre os atores e instituições políticas, mas sobre o próprio regime democrático.

Do ponto de vista do método, os instrumentos disponíveis conseguiram captar as mudanças nas amostras coletadas para o apoio ao sistema democrático. A utilização de séries temporais - tendo em vista que este artigo analisou somente dois anos - tem potencial para, não somente colocar à prova a força das ferramentas de análise escolhidas, como para a captação de tendências de longo prazo. No entanto, faz-se necessário aprofundar a análise de conteúdo, para todos os períodos da cobertura política midiática, tarefa instigante, mas de longo prazo.

Diante desses resultados, salta também aos olhos a necessidade de conformação de banco de dados nacionais contínuos sobre os cidadãos e seus posicionamentos políticos. Pesquisas como WVS e Lapop são fruto da curiosidade de centro de pesquisas externos. No Brasil, tem-se somente o ESEB, a cada quatro anos, e iniciativas como as de Moisés (2005, 2010) sobre a qualidade da democracia. Pesquisas estruturadas, contínuas e abertas à comunidade acadêmica seriam de grande valia para o estudo dos efeitos da mídia e da democracia, bem como outras áreas das ciências sociais. Afinal, dados são instrumentos necessários para consecução do que King, Keohane e Verba (1994) delinearam como um dos objetivos da ciência: dizer algo relevante sobre a realidade.

\section{Referências bibliográficas}

Aldé, A., \& Vasconcellos, F. (2008). Ao vivo de Brasília: escândalo político, oportunismo midiático e circulação de notícias. Revista de Ciências Sociais, 39(2), 61-69.

Almond, G. A., \& Verba, S. (1989). The Civic Culture. Newbury Park: Sage Publications.

Althaus, S. L. (2006). Americans News Consumption during Times of National Crisis. Political Science and Politics, 35(3), 517-521. 
Baum, M. A., \& Kernell, S. (1999). Has cable ended the golden age of presidential television? American Political Science Review, 93(1), 99-114.

Bennett, S., Rhine, S. L., Flikinger, R. S., \& Bennett, L. (1999). "Video Malaise" Revisited: Public Trust in the Media and Government. International Journal of Press/Politics, 4(4), 8-23.

Bentes, I. (2014). Estéticas Insurgentes e Mídia-Multidão. Liinc Em Revista, 10(1), 330-343.

Biroli, F., \& Miguel, L. F. (2013). Meios de Comunicação, Voto e Conflito Político no Brasil. Revista Brasileira de Ciências Sociais, 28(81), 77-95.

Borges, T. G. F. (2015). Entre o espetáculo e o debate público: enquadramentos sobre as manifestações de junho de 2013 no Jornal Nacional e no Repórter Brasil. Universidade Federal do Rio Grande do Sul.

Brasil. (2014). Pesquisa Brasileira de Mídia 2015: hábitos de consumo de mídia pela população brasileira. Brasília: Assessoria de Pesquisa de Opinião Pública - Secretaria de Comunicação Social da Presidência da República.

Bringel, B. (2013). Miopias, sentidos e tendências do levante brasileiro de 2013. Insight Inteligência, 62, 42-53.

Bringel, B., \& Geoffrey, P. (2015a). Junho de 2013... dois anos depois: Polarização, impactos e reconfiguração do ativismo no Brasil. Nueva Sociedad, 259, 4-17.

Bringel, B., \& Geoffrey, P. (2015b). Les mobilisations de 2013 au Brésil: vers une reconfiguration de la contestation. Brésil(S), (7), 7-18.

Capella, J. N., \& Jamieson, K. H. (1997). Spiral of Cynicism: the Press and the Public Good. New York: Oxford University Press.

Carlos, E. N. (2015). A mídia e as manifestações de junho de 2013: uma análise de produtos midiáticos. Faculdade Cásper Líbero.

Ceobanu, A. M., Wood, C. H., \& Ribeiro, L. (2011). Crime Victimization and Public Support for Democracy: Evidence from Latin America. International Journal of Public Opinion Research, 23(1), 56-78.

Cohen, Y., \& Santana, M. (2015). Du Brésil au monde et retour: mouvements sociaux localisés et en résonance. Brésil(S), (7), 103-122.

Converse, P. E. (1962). Information Flow and the Stability of Partisan Attitudes. Public Opinion Quarterly, $26,578-599$.

Converse, P. E. (1964). The Nature of Belief Systems in Mass Politics. In D. E. Apter (Ed.), Ideology and Discontent (pp. 206-261). New York: The Free Press.

Czitrom, D. J. (1982). Media and the American Mind: From Morse to McLuhan. University of North Carolina Press.

DellaVigna, S., \& Kaplan, E. (2007). The Fox News effect: media bias and voting. The Quarterly Journal of Economics, 122(3), 1187-1234.

Druckman, J. N., Peterson, E., \& Slothuus, R. (2013). How Elite Partisan Polarization Affects Public Opinion Formation. American Political Review, 1071). https://doi.org/10.1017/S0003055412000500

Easton, D. (1975). A Re-Assessment of the Concept of Political Support. British Journal of Political Science, 5(4), 435-457.

Figueiredo Filho, D. B., \& Silva Júnior, J. A. (2010). Visão além do alcance: uma introdução à análise fatorial. Opinião Pública, 16(1), 160-185. 
Fontanetto, R. M. B., \& Bezerra, C. C. C. (2016). A cidade em narrativas: jornalismos tradicional e cidadão durante as 'Jornadas de Junho' de 2013 no Brasil. Chasqui. Revista Latinoamericana de Comunicación, (131), 349-362.

Gomes, W. (2004). Transformações da Política na Era da Comunicação de Massa. São Paulo: Paulus.

Gomes, W. (2008). Capital Social, Democracia e Televisão em Robert Putnam. In Comunicação e Democracia: Problemas e Perspectivas (pp. 221-274). São Paulo: Paulus.

Iyengar, S., \& Hahn, K. S. (2009). Red media, blue media: evidence of ideology selectivity in media use. Journal of Communication, 59, 19-39.

Iyengar, S., \& Westwood, S. J. (2015). Fear and Loathing across Party Lines: New Evidence on Group Polarization. American Journal of Political Science, 59(3), 690-707.

King, G., Keohane, R. O., \& Verba, S. (1994). Designing social inquiry: scientific inference in qualitative research. Princeton: Princeton University Press.

Klingemann, H.-D. (1999). Mapping Political Support in the 1990s: A Global Analysis. In P. Norris (Ed.), Critical Citizens: Global Support for Democratic Government (pp. 31-56). New York: Oxford University Press.

Lazarsfeld, P. F., Berelson, B., \& Gaudet, H. (1948). The People's Choice: How the Voter Makes up His Mind in a Presidential Election (6th ed.). New York: Columbia University Press.

Lima, M. D. V. de, \& Loose, E. B. (2014). Metamorfoses no jornalismo: aspectos da cobertura dos protestos de rua de junho de 2013. Conexão - Comunicação e Cultura, 13(25), 35-53.

Mcallister, I. (1999). The Economic Performance of Governments. In P. Norris (Ed.), Critical Citizens: Global Support for Democratic Government (pp. 187-203). New York: Oxford University Press.

Mesquita, N. C. (2008). Mídia e Democracia no Brasil: Jornal Nacional, crise política e confiança nas Instituições. Doutorado em Ciência Política - Universidade de São Paulo, São Paulo.

Miguel, L. F. (2002). Os meios de comunicação e a prática política. Lua Nova, (55-56), 155-184.

Miguel, L. F. (2008). A mídia e o declínio da confiança na política. Sociologias, (19), 250-273.

Miguel, L. F., \& Coutinho, A. de A. (2007). A Crise e Suas Fronteiras: Oito Meses de "Mensalão" nos Editorais dos Jornais. Opinião Pública, 13(1), 97-123.

Mingoti, S. A. (2005). Análise de Dados Através de Métodos de Estatística Multivariada: Uma Abordagem Aplicada. Belo Horizonte: Editora UFMG.

Moisés, J. A. (2005). A desconfiança nas instituições democráticas. Opinião Pública, 11(1), 33-63. https://doi.org/10.1590/S0104-62762005000100002

Moisés, J. A. (2010). Os significados da democracia segundo os brasileiros. Opinião Pública, 16(2), 269309. https://doi.org/10.1590/S0104-62762010000200001

Moretzsohn, S. D. (2014). As sombras de junho. Liinc Em Revista, 10(1), 163-175.

Mundim, P. S. (2010). A teoria da dinâmica da opinião pública de John R. Zaller: aplicações para o caso brasileiro. ContemporâNea, 72$), 1-29$.

Mundim, P. S. (2014). Mídia, Voto e Eleições Presidenciais no Brasil. In R. Bonifácio, G. Casalecchi, \& C. de Deus (Eds.), O Voto Para Presidente no Brasil: Condicionantes e Fatores Explicativos (pp. 217256). Íthala/Edufpi.

Neuman, W. R., \& Guggenheim, L. (2011). The Evolution of Media Effects Theory: A Six-Stage Model of Cumulative Research. Communication Theory, 21, 169-196. 
Norris, P. (1996). Does Television Erode Social Capital? A Reply to Putnam. PS: Political Science \& Politics, 29(3), 474-480.

Norris, P. (1999). Critical Citizens: Global Support for Democratic Government. New York: Oxford University Press.

Norris, P. (2000). A Virtuous Circle: Political Communications in Postindustrial Societies. Cambridge: Cambridge University Press.

Pinto, C. R. J. (2017). A trajetória discursiva das manifestações de rua no Brasil (2013-2015). Lua Nova, $100,119-153$.

Presusso, M. A., \& Narvaes, V. B. (2015). Les journées de(puis) juin 2013. Brésil(S), (7), 19-38.

Prior, M. (2005). News vs. Entertainment: How Increasing Media Choice Widens Gaps in Political Knowledge and Turnout. American Journal of Political Science, 49(3), 577-592.

Prior, M. (2007). Post-Broadcast Democracy: How Media Choice Increases Inequality in Political Involvement and Polarizes Elections. Cambridge University Press.

Prior, M. (2013). Media and Political Polarization. Annu. Rev. Polit. Sci, 16. https://doi.org/10.1146/annurevpolisci-100711-135242

Putnam, R. (1995a). Bowling Alone: America's Declining Social Capital. Journal of Democracy, 6(1), 65-78.

Putnam, R. (1995b). Tuning In, Tuning Out: The Strange Disappearance of Social Capital in America. Political Science and Politics, 274), 664-683.

Rennó, L. (2013). Responsividade e Qualidade da Democracia no Brasil. In J. C. Cardoso Jr. \& G. Bercovici (Eds.), República, Democracia e Desenvolvimento: Contribuições ao Estado Brasileiro Contemporâneo (pp. 89-126). Brasília: Ipea.

Rubim, A. A. C., \& Azevedo, F. A. (1998). Mídia e Política no Brasil: Textos e Agenda de Pesquisa. Lua Nova, 43(1), 189-216.

Santos, F. (2013). Do protesto ao plebiscito: uma avaliação crítica da atual conjuntura brasileira. Novos Estudos Cebrap, (96), 14-25.

Scherer-Warren, I. (2014). Manifestações de rua no Brasil 2013: encontros e desencontros. Cadernos CRH, 2771), 417-429.

Schlegel, R. (2005). Mídia, confiança política e mobilização. Dissertação de Mestrado em Ciência Política Universidade de São Paulo, São Paulo.

Schneider, M., Perissé, C., \& Kleinsorgen, N. (2014). Trotsky e o Facebook: as "jornadas de junho", o problema da estratégia e a disputa nas (novas e velhas) mídias. Liinc Em Revista, 10(1), 69-85.

Singer, A. (2013). Brasil, junho de 2013: Classes e ideologias cruzadas. Novos Estudos Cebrap, (97).

Sodré, N. W. (2004). História da Imprensa no Brasil. Rio de Janeiro: Mauad Editora.

Souza, C. A. de, \& Morales, O. E. T. (2016). A cobertura do "Vem Pra Rua " pelas revistas nacionais em 2013: uma análise das capas. Revista Estudos de Comunicação, 1742), 23-41. https://doi.org/10.037/comunicacao.17.043.AO02

Souza, H. da C. A. de, \& Lima, M. R. D. V. de. (2014). A democracia em crise: o olhar da comunicação sobre as manifestações de rua no Brasil em 2013. Liinc Em Revista, 10(1), 96-108.

Stroud, N. J. (2011). Niche News: the Politics of News Choice. New York: Oxford University Press.

Tavares, F. M. M., Roriz, J. H. R., \& Oliveira, I. C. de. (2016). As jornadas de maio em Goiânia: para além de uma visão sudestecêntrica do junho brasileiro em 2013. Opinião Pública, 22(1), 140-166. 
Turgeon, M., \& Oliveira, C. (2015). Ideologia e Comportamento Político no Eleitorado Brasileiro. Opinião Pública, 21(3), 574-600.

Wood, T., \& Oliver, E. (2012). Toward a More Reliable Implementation of Ideology in Measures of Public Opinion. Public Opinion Quarterly, 76(4), 636-662.

Zaller, J. R. (1991). Information, Values, and Opinion. American Political Science Review, 85(4), 1215-1237.

Zaller, J. R. (1992a). The Nature and Origins of Mass Opinion (13th ed.). Cambridge University Press.

Zaller, J. R. (1992b). The Nature and Origins of Mass Opinion (13th ed.). Cambridge: Cambridge University Press.

Zaller, J. R., \& Price, V. (1993). Who Gets the News? Alternative Measures of News Reception and Their Implications For Research. Public Opinion Quarterly, 57, 133-164.

Zanotti, C. A. (2014). Entre baderneiros e cidadãos: a cobertura da imprensa nas manifestações de junho de 2013. Revista Comunicação e Sociedade, 35(3), 93-116.

Ziller, J. (2014). Contrastes entre as imagens do Jornal Nacional e as independentes: diversidade informativa nos protestos iniciais das Jornadas de Junho. Liinc Em Revista, 10(1), 301-316.

\section{Apêndice}

Tabela 5: Determinantes do apoio à democracia no Brasil

\begin{tabular}{|c|c|c|c|}
\hline & $\begin{array}{l}\text { Adesão à } \\
\text { comunidade } \\
\text { política }\end{array}$ & $\begin{array}{l}\text { Apoio à } \\
\text { democracia }\end{array}$ & $\begin{array}{l}\text { Performance } \\
\text { do regime }\end{array}$ \\
\hline \multirow[t]{2}{*}{ Sexo (Homem) } & $-0.72^{*}$ & 0.018 & -0.19 \\
\hline & $(0.22)$ & $(0.07)$ & $(0.13)$ \\
\hline \multirow[t]{2}{*}{ Grupo de idade } & -0.17 & 0.023 & -0.071 \\
\hline & $(0.10)$ & $(0.03)$ & $(0.06)$ \\
\hline \multirow[t]{2}{*}{ Ensino médio } & 0.25 & $-0.39 *$ & 0.069 \\
\hline & $(0.46)$ & $(0.15)$ & $(0.27)$ \\
\hline \multirow[t]{2}{*}{ Ensino superior } & -0.52 & 0.16 & -0.45 \\
\hline & $(0.64)$ & $(0.21)$ & $(0.37)$ \\
\hline \multirow[t]{2}{*}{ Porte do Município } & $-0.33^{*}$ & -0.038 & $-0.17 *$ \\
\hline & $(0.14)$ & $(0.04)$ & $(0.08)$ \\
\hline \multirow[t]{2}{*}{ Economia do país } & 0.10 & 0.080 & $0.19 *$ \\
\hline & $(0.16)$ & $(0.05)$ & $(0.09)$ \\
\hline \multirow[t]{2}{*}{ Economia pessoal } & 0.18 & -0.042 & -0.031 \\
\hline & $(0.16)$ & $(0.05)$ & $(0.09)$ \\
\hline \multirow[t]{2}{*}{ Avaliação Dilma } & $0.94 *$ & $0.13^{*}$ & $1.35^{*}$ \\
\hline & $(0.12)$ & $(0.04)$ & $(0.07)$ \\
\hline \multirow[t]{2}{*}{ Esquerda } & $-1.07 *$ & $-0.51^{*}$ & -0.24 \\
\hline & $(0.47)$ & $(0.15)$ & $(0.27)$ \\
\hline Direita & $1.00 *$ & -0.27 & $0.97 *$ \\
\hline
\end{tabular}




\begin{tabular}{|c|c|c|c|}
\hline & $(0.43)$ & $(0.14)$ & $(0.25)$ \\
\hline \multirow[t]{2}{*}{ Sem ideologia } & -0.14 & -0.22 & 0.36 \\
\hline & $(0.47)$ & $(0.15)$ & $(0.25)$ \\
\hline \multirow[t]{2}{*}{ Interesse por política } & $0.41^{*}$ & $0.20^{*}$ & $0.39 *$ \\
\hline & $(0.13)$ & $(0.04)$ & $(0.07)$ \\
\hline \multirow[t]{2}{*}{ Participação } & $0.27 *$ & $-0.10 *$ & 0.092 \\
\hline & $(0.13)$ & $(0.04)$ & $(0.07)$ \\
\hline \multirow[t]{2}{*}{ Vítima de crime } & $-0.79 *$ & -0.021 & -0.30 \\
\hline & $(0.29)$ & $(0.09)$ & $(0.17)$ \\
\hline \multirow[t]{2}{*}{ Sensação de segurança } & $0.43^{*}$ & $0.090 *$ & $0.28^{*}$ \\
\hline & $(0.12)$ & $(0.04)$ & $(0.07)$ \\
\hline \multirow[t]{2}{*}{ Confiança no Judiciário } & $1.25^{*}$ & 0.0064 & $0.58 *$ \\
\hline & $(0.12)$ & $(0.04)$ & $(0.07)$ \\
\hline \multirow[t]{2}{*}{ Atenção Política } & $-0.54 *$ & $0.16^{*}$ & 0.042 \\
\hline & $(0.22)$ & $(0.07)$ & $(0.15)$ \\
\hline \multirow[t]{2}{*}{ Internet } & $-0.29 *$ & -0.012 & $-0.18^{*}$ \\
\hline & $(0.11)$ & $(0.03)$ & $(0.08)$ \\
\hline \multirow[t]{2}{*}{ Atenção às notícias } & 0.27 & $0.35^{*}$ & 0.0018 \\
\hline & $(0.15)$ & $(0.05)$ & $(0.11)$ \\
\hline \multirow[t]{2}{*}{ Pesquisas } & $-0.63^{*}$ & $-0.23 *$ & $-0.95^{*}$ \\
\hline & $(0.25)$ & $(0.08)$ & $(0.16)$ \\
\hline \multirow[t]{2}{*}{ Esquerda $\times$ Médio } & 0.053 & $0.46^{*}$ & -0.12 \\
\hline & $(0.60)$ & $(0.20)$ & $(0.34)$ \\
\hline \multirow[t]{2}{*}{ Esquerda $\times$ Superior } & 0.87 & 0.33 & 0.43 \\
\hline & $(0.85)$ & $(0.28)$ & $(0.49)$ \\
\hline \multirow[t]{2}{*}{ Direita $\times$ Médio } & -0.18 & $0.49 *$ & -0.061 \\
\hline & $(0.57)$ & $(0.18)$ & $(0.33)$ \\
\hline \multirow[t]{2}{*}{ Direita $\times$ Superior } & 0.062 & 0.24 & -0.49 \\
\hline & $(0.81)$ & $(0.26)$ & $(0.47)$ \\
\hline \multirow[t]{2}{*}{ Atenção às notícias $\times$ Lapop 2014} & $-0.60 *$ & $-0.32 *$ & 0.065 \\
\hline & $(0.23)$ & $(0.08)$ & $(0.15)$ \\
\hline \multirow[t]{2}{*}{ Internet $\times$ Lapop 2014} & 0.029 & -0.011 & -0.053 \\
\hline & $(0.13)$ & $(0.04)$ & $(0.08)$ \\
\hline \multirow[t]{2}{*}{ Atenção Política × Lapop 2014} & 0.18 & -0.14 & -0.20 \\
\hline & $(0.25)$ & $(0.08)$ & $(0.17)$ \\
\hline \multirow[t]{2}{*}{ Constante } & $7.58^{*}$ & $2.78^{*}$ & $2.84^{*}$ \\
\hline & $(1.06)$ & $(0.35)$ & $(0.72)$ \\
\hline $\mathrm{N}$ & 2553 & 2527 & 1943 \\
\hline $\mathrm{R}^{2}$ ajustado & 0.183 & 0.065 & 0.395 \\
\hline
\end{tabular}

Fonte: Lapop 2012 e 2014. Erros-padrão entre parênteses. ${ }^{*} p<0.05$ 